\title{
Numerical Analyses to Investigate the Feasibility and Effectiveness in Using Heat Pipe Embedded End Mills
}

\author{
Yong-Bin Liu1,3 - Lin Zhu1,2* - Tien-Chien Jen² - Ji-Wen Zhao ${ }^{1}-$ Yi-Hsin Yen² \\ ${ }^{1}$ School of Electrical Engineering and Automation, Anhui University, China \\ 2 Mechanical Engineering Department, University of Wisconsin, USA \\ ${ }^{3}$ Department of Precision Machinery and Precision Instrumentation, University of Science and Technology of China, China
}

In this paper, the feasibility and effectiveness of heat pipe cooling in end milling operations are investigated. A new embedded heat pipe technology was utilized to remove the heat generated at the tool-interface in end milling processes. Numerical studies involved four cases, including dry milling, fluid cooling, heat-pipe cooling and heat-pipe cooling with cutting fluid supplied. The thermal, structural static and dynamic characteristics of the end-mill were investigated using a numerical calculation with Fast Finite Element (FFE) plus solvers based on explicit finite element analysis software. The results demonstrate that the heat pipe end-mill is most feasible and effective in the actual end milling processes.

Keywords: heat pipe cooling, feasibility and effectiveness, end-mill, thermal and structural analyses

\section{O INTRODUCTION}

The thermal aspect that occurs on the cutting tool during the material removal processes is a traditional concern because cutting temperatures strongly influence tool wear, tool life, workpiece surface integrity, chip formation mechanism and contribute to the thermal deformation of the cutting tool.

In end milling operations, tool temperatures become even more important due to the fact that the tool used in the milling operation undergoes thermal shock in each revolution. The fast heating and cooling of the tool at work may result in considerable temperature variations in cutting edge, and furthermore, the heat generated during chip formation does not flow easily through the workpiece and chip. Consequently, this increases the percentage of heat going to the tool, makes the temperature variation even higher than before, and causes cracking perpendicular to the cutting edge [1] to [3]. These increased cracks result either in chipping or, occasionally, in breakage of the cutting edge. To extend tool life, the most common approach is the use of cutting fluids flooding through the cutting zone. However, cutting fluids often induce significantly negative impacts on environment, safety, operators' health and operating cost and especially the use of water-based cutting fluids in end milling operations usually increases temperature variation and, hence, thermal cracks [2] and [4].

Heat pipe cooling is considered to be an effective alternative to conventional methods for removing heat from a tool tip, which allows machining operations to be implemented in a dry and "green" fashion [5] and [6]. A heat pipe is composed of a sealed container (pipe wall and end caps), a wick structure, and a small amount of working fluid in equilibrium with its own vapor. The heat pipe is generally divided into three sections: evaporator section, adiabatic (transport) section and condenser section, as illustrated in Fig. 1 [5]. First, the working fluid is vaporized by the external heat load on the evaporator section. Then, the resulting vapor pressure drives the vapor from the evaporator section to the condenser section, at which the vapor condenses and releases its latent heat of vaporization to the low temperature environment. Finally, the condensed working fluid is pumped back by capillary pressure from the meniscus in the wick structure. Note that heat transport can be continuous if there is sufficient capillary pressure generated to drive the condensed liquid back to the evaporator.

Using heat pipes for heat removal in machining has been occasionally reported. Judd et al. [7] investigated turning of steel with a heat pipe embedded in a tool holder and reported that the heat pipe is found effective in reducing the tool-holder temperature by $30 \%$. Chiou et al. [8] and [9] conducted a finite element analysis and an experimental study of heatpipe cooling in steel machining using carbide tools. The authors concluded that the heat pipe, embedded in a cutting insert, is able to alleviate the cutting tool temperatures, reduce tool wear, and prolong the tool life. For drilling, Jen, et al. [2] compared heat-pipe cooling with dry drilling in the actual machining operations numerically and experimentally and claimed that the heat pipe in the drill can reduce the drill temperature by 30 to $50 \%$. To the best of our knowledge, however, there is a lack of additional published research on all of various cooling conditions in the practical drilling processes. 
In this paper, the feasibility and effectiveness of heat-pipe cooling in end milling operations are investigated. Numerical studies focus on four different kinds of cooling cases: (1) dry milling, (2) fluid cooling, (3) heat-pipe cooling, and (4) heatpipe cooling with cutting fluid supplied. The thermal, structural static and dynamic characteristics of the end-mill are predicted using a numerical calculation with Fast Finite Element (FFE) plus solvers based on explicit finite element analysis software.

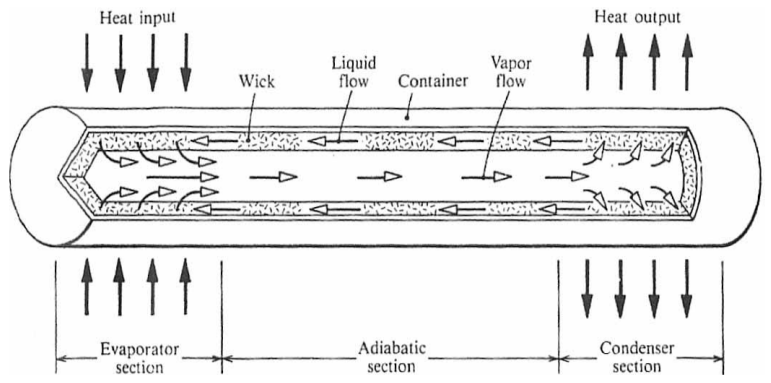

Fig. 1. A conventional Heat Pipe [5]

1 FEA MODEL

\subsection{Model Geometry}

The model geometries of end-mills with and without a heat-pipe were constructed in SolidWorks by means of feature-based modeling method. In terms of the real tool profile as shown in Fig. 2, the specifications of the tool are presented as follows (Fig. 3a):

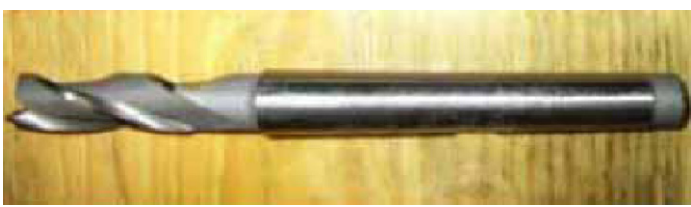

Fig. 2. Three-flute end mill

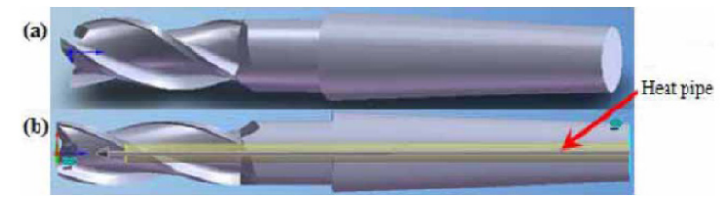

Fig. 3. Three-flute end-mill; a) without and b) with a heat pipe

- Three-flute tool, $20 \mathrm{~mm} \phi_{\text {head }}, 18 \mathrm{~mm} \phi_{\text {end }}, 125$ mm long.

- Rake angle $\gamma=0^{\circ}$, clearance angle $\alpha=12^{\circ}$, helix angle $\beta=30^{\circ}$.

- Hard alloy material.

- Based on [6] to [10], the dimensions of the heat pipe embedded in the end-mill are $5.5 \mathrm{~mm}$ $\phi_{\text {heatpipe }}, 110 \mathrm{~mm} l_{\text {heatpipe }}$ (Fig. 3b).

\subsection{FEA Modeling}

For the purpose of obtaining accurate numerical simulation results, the strategy in this study is based on high-density mesh, in which each solid element has 10 nodes for regions requiring high resolution (Fig. 4). Four points Jacobian Check method for the distortion level of tetrahedral elements was used to mesh the entire tool and especially fine meshing at the tool tip. Fig. 5 shows the mesh distribution in the end-mill using COSMOS $\backslash$ works. It is worth pointing out 8123 elements and 13822 nodes were used for the end-mill, while 8812 elements and 14307 nodes for the heat pipe end-mill.

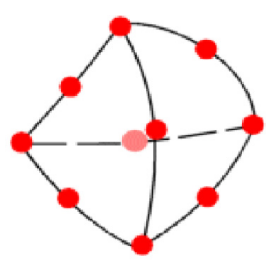

Fig. 4. Parabolic solid element

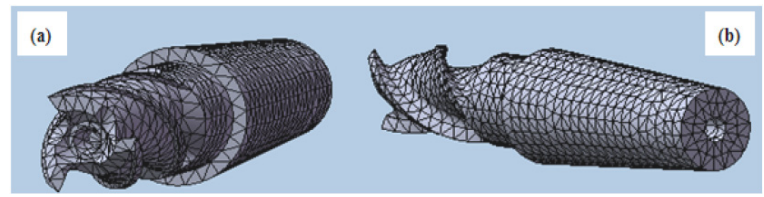

Fig. 5. Meshes of a) solid end-mill geometry and b) heat pipe endmill geometry

\section{RESULTS AND DISCUSSION}

\subsection{Parameters and Computing Time}

Only one of the three cutting edges needs to be numerically simulated in this study due to the endmill being symmetrical and the cutting process being interrupted. Stainless steel was chosen for the workpiece material. Down-milling with passes in the longitudinal direction of the workpiece was used as a result of the fact that the thermal impact to the cutting tool during heating is larger in down milling than in up milling [11] to [13]. The associated parameters in the foregoing end milling process are presented as follows:

- Spindle speed $n=5,000 \mathrm{rpm}$, depth of cut $t=5$ $\mathrm{mm}$, width of cut $B=20 \mathrm{~mm}$, feed per tooth $S_{z}=$ $0.1 \mathrm{~mm} /$ tooth. 
- Based on [10], the loads acting on the cutting edge are presented below (Fig. 6): $F_{t}=1,377 \mathrm{~N}$, $F_{a}=689 \mathrm{~N}, F_{r}=565 \mathrm{~N}$.

- The thermal and physical properties of the tool material are:

$$
\begin{aligned}
& E=6 \times 10^{11} \mathrm{~Pa}, \mu=0.33, \\
& \rho=14.7 \times 10^{3} \mathrm{~kg} / \mathrm{m}^{3}, \sigma_{b b}=1,470 \mathrm{MPa}, \\
& C_{p}=50 \mathrm{~J} /(\mathrm{kg} \cdot \mathrm{k}), \lambda=5 \times 10^{-6} / \mathrm{K}, \\
& K=35 \mathrm{~W} /(\mathrm{m} \cdot \mathrm{k}) .
\end{aligned}
$$

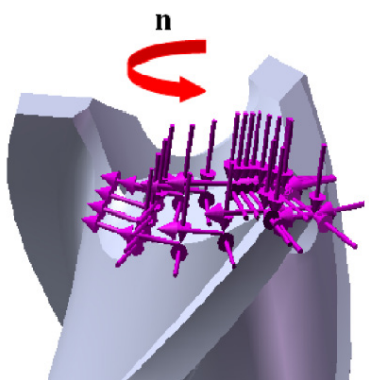

Fig. 6. The loaded end mill

For end milling, an intermittent calculation was conducted in this study. $H_{\text {tooth }}$ of the end mill is equal to $3.06 \mathrm{~mm}$ (Fig. 7), so $T_{\text {cutting }}$ for one cutting edge was calculated as $0.0006 \mathrm{~s}$ in each tool revolution dependent on the geometric parameters of the standard 3-flute end-mill and the prescribed operation conditions. This time actually represents the milling period from the cutting start point $A$ to the cutting end point B, as illustrated in Fig. 7. A total calculation time of $0.0239 \mathrm{~s}$ elapsed for all simulations in this paper.

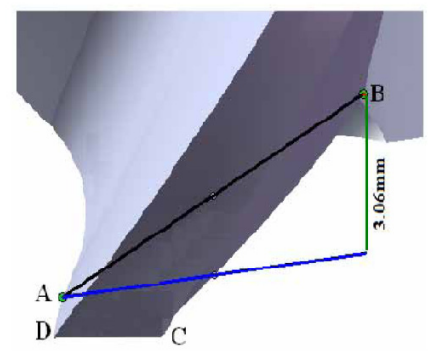

Fig . 7. Three-flute tool tip

\subsection{Thermal Analysis}

\subsubsection{Thermal Boundary Conditions for a Heat Pipe in an End-Mill}

Based on [6], the heat pipe and the end mill in this study, for simplicity, are modeled as concentric cylinders due to their similar configurations as shown in Fig. 8. Heat generation, for simplicity, is modeled as a cylindrical band heat source surrounding the cylinder due to the fact that non-cutting period is very short in high-speed end milling operations (Fig. 8 ), although end milling is an interrupted cutting process. According to [6], the heat input at the tool tip is included in the banded heat input zone, the heat input in the z-direction through the top cap is assumed to be negligible, the heat pipe in the center of the cylinder tool is modeled as a small hollow cylinder with the pipe wall maintained at a fixed temperature, and the temperature dependence in this direction can be neglected due to the symmetry in the angular direction.

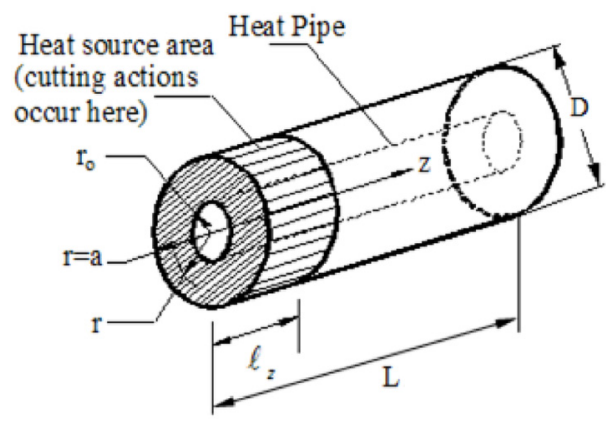

Fig. 8. Physical configuration of an idealized end mill with a heatpipe [6]

Thus, the following thermal boundary conditions are applied [6] and [7]:

- At the end caps of the tool, an insulated boundary condition and a constant temperature are imposed, respectively:

$$
\left.\frac{\partial T}{\partial z}\right|_{z=0}=0,\left.\quad T\right|_{z=L}=T_{o} .
$$

- In the cutting zone area of heat pipe tool, a constant heat flux $q^{\prime \prime}{ }_{c}$ is applied:

$$
\left.k_{T} \frac{\partial T}{\partial r}\right|_{r=a}=q_{C}^{\prime \prime} \text { for } 0 \leq z \leq \ell_{z} .
$$

- On the surface area outside the heat input zone, an adiabatic condition is exerted:

$$
\left.\frac{\partial T}{\partial r}\right|_{r=a}=0 \text { for } z \geq \ell_{z}
$$

- The temperature on the inner cylinder surface is fixed:

$$
\left.T\right|_{r=r_{o}}=T_{h p} \text { for } z \geq \ell
$$

- The following boundary condition is applied for the end cap of the heat pipe:

$$
\left.T\right|_{z=\ell}=T_{h p} \quad \text { for } \quad 0 \leq r \leq r_{o},
$$


and the initial condition is:

$$
\left.T\right|_{\tau=0}=T_{o},
$$

where $T_{o}$ is the ambient temperature, $T_{h p}$ is the heat pipe surface temperature (boiling temperature of the working fluid).

\subsubsection{Temperature Distribution and Thermal Stress}

The ambient temperature was set to be constant at $25^{\circ} \mathrm{C}$, and $100^{\circ} \mathrm{C}$ for the heat pipe under full operation condition with water as the working fluid. In view of the foregoing operation parameters, a calculated heat input of $8287 \mathrm{~W}$ was applied at the tip of the tool (Fig. 6 ), and with about $14.5 \%$ heat that enters the tool [14] to [15]. In addition, on all other surfaces imposed were the thermal boundary conditions seen above.

Seen from Fig. 9, for all the numerical simulation cases in this study, the peak temperatures occur at the end-mill tips, and the temperature at the outer tip is much higher than that at the inner tip.

The calculated results agree well with the actual milling operations. It is basically due to the facts as follows: new surface in end milling operations is generated as each tooth cuts away an arc-shaped segment. The undeformed chip thickness in the foregoing process is not constant but varies with tool rotation. The tool-chip constant length on the rake face varies with time (Fig. 10). According to Stephenson et al. [16], an end mill is modeled as a semi-infinite rectangular corner, $x \geq 0, y \geq 0, z \geq 0$, heated by a heat flux as shown in Fig. 11. Thus, the heat source dimension in the $\mathrm{x}$-axis direction is a function of cutting time. For down milling processes, the depth of cut is the largest at the beginning of the cutting, and approximates 0 at the end, as shown in Fig. 12.

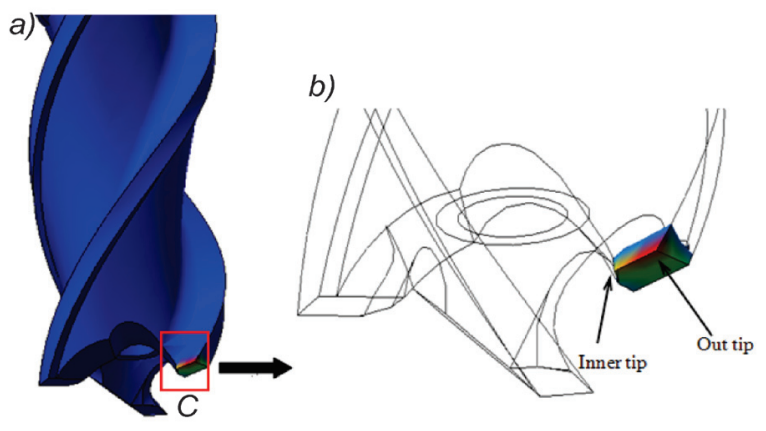

Fig. 9. a) Temperature distribution on the tool tip; b) detailed $C$ of a); magnified view of the temperature distribution on the tool tip

Fig. 13 shows the temperature variations at the outer tip with time. As observed, the maximum temperatures are approximate $1027^{\circ} \mathrm{C}(1300 \mathrm{~K})$ for dry milling, $767{ }^{\circ} \mathrm{C}(1040 \mathrm{~K})$ for fluid cooling, 737
${ }^{\circ} \mathrm{C}(1010 \mathrm{~K})$ for heat-pipe cooling, and $637{ }^{\circ} \mathrm{C}(910$ $\mathrm{K})$ for heat-pipe cooling with coolant, respectively. Compared 13b) with 13c), it could be inferred that the temperature using heat pipe does reduce faster than that using coolant (see the black arrows). This is because most of heat generated on the end-mill tip is quickly removed dependent on convection heat transfer by means of heat pipe. From the effect of the peak temperature viewpoint, the heat pipe cooling therefore outperforms the cases with dry milling, even with effective coolant, respectively.

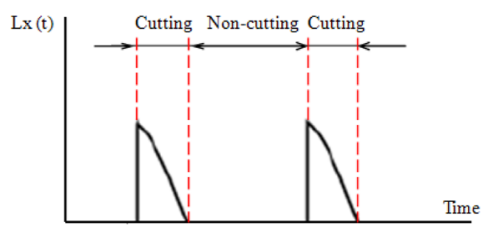

Fig. 10. Variation in tool-chip contact length in down milling

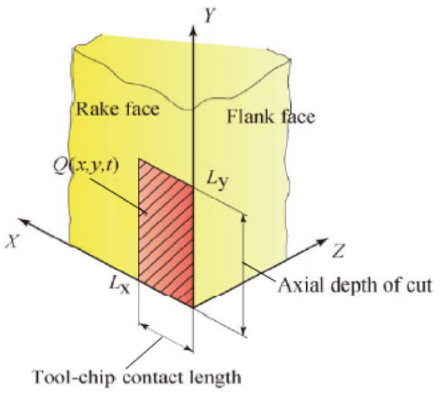

Fig. 11. Tool insert model

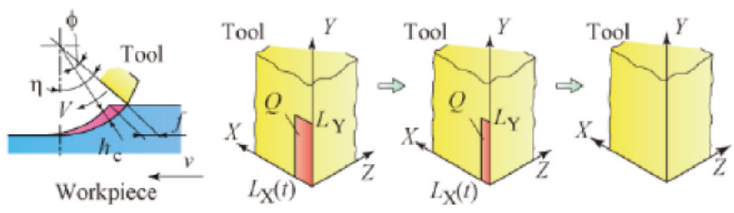

Fig. 12. Variation of heat source area in down milling

Fig. 14 shows schematic for the variations of the thermal stress distributions at the end-mill tips under various cooling conditions. All of the maximum thermal stresses also occur at the tool tips within the equivalent time as above and especially the thermal stress at the outer tip is larger than that at the inner tip. As observed, the thermal stresses at the outer tip are approximately $650,500,480$ and $340 \mathrm{MPa}$ for dry milling, fluid cooling, heat-pipe cooling, and heatpipe cooling with coolant, respectively.

From Figs. 13 and 14, it can be seen that the peak temperature on the tool tip decreases from $1027^{\circ} \mathrm{C}$ in dry milling to $737{ }^{\circ} \mathrm{C}$ in heat-pipe cooling by about $29 \%$ based on the equivalent amount of heat input, 

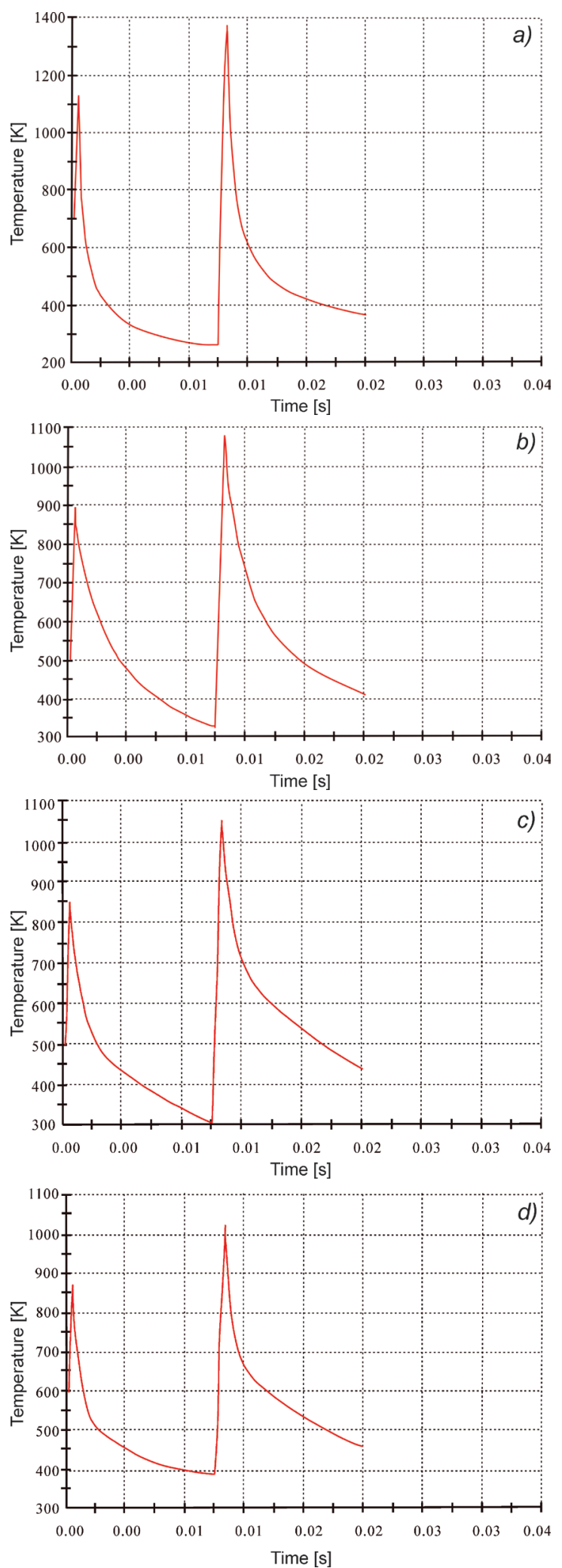

Fig. 13. Plots between the maximum temperatures on the tool tip vs. time; a) dry milling,; b) fluid cooling; c) heat pipe cooling, and d) heat pipe cooling with coolant
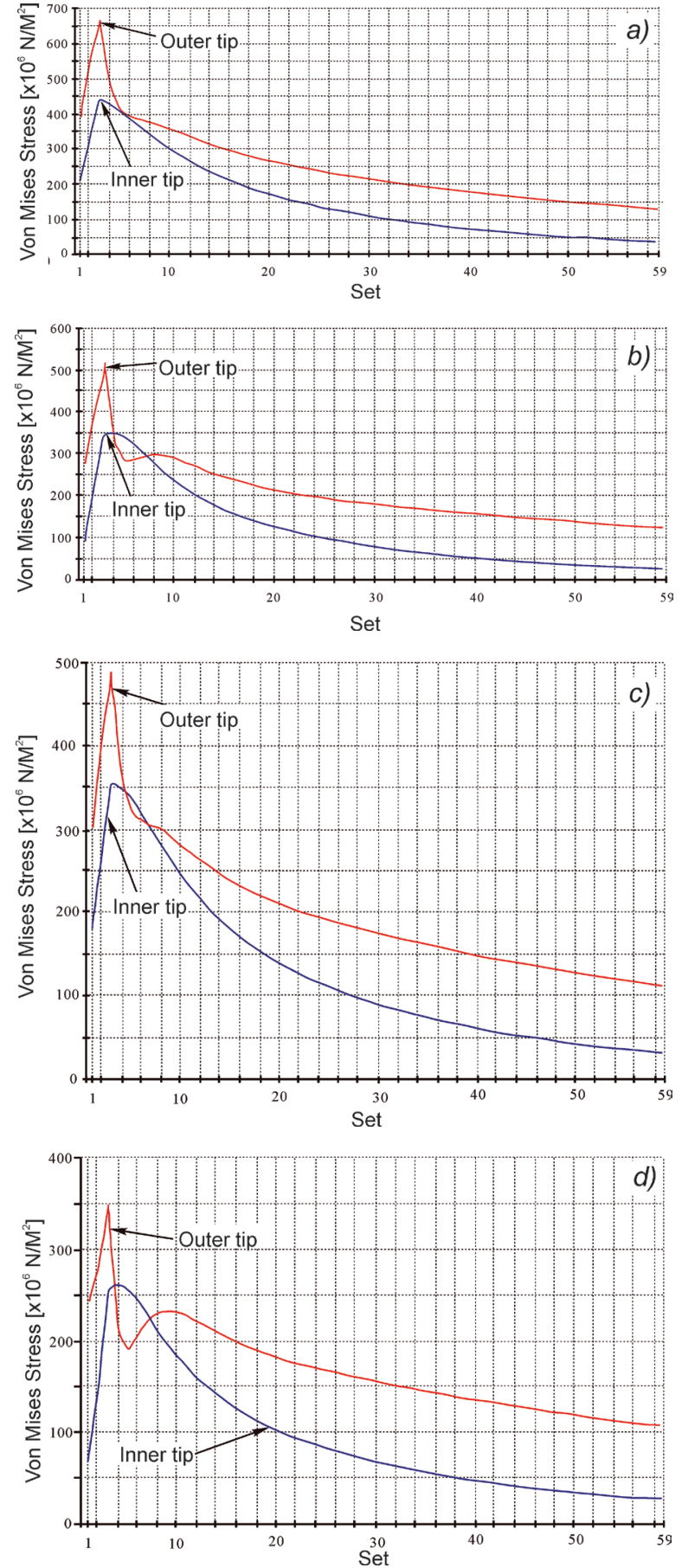

Fig. 14. The maximum thermal stresses in the cutting time: a) dry milling; b) fluid cooling; c) heat-pipe cooling; and d) heat- pipe cooling with coolant

and that the maximum thermal stress also reduces from $650 \mathrm{MPa}$ for dry milling to $480 \mathrm{MPa}$ for the heat-pipe cooling by an approximate factor of 1.4 under the same cooling conditions. Therefore, it can be concluded that with the aid of a heat pipe in the end milling operations, the probability of tool failure 
can be significantly reduced due to lower maximum temperature and thermal stress.

\subsection{Structural Static and Dynamic Analysis}

In end milling operations, the undeformed chip thickness varies with tool rotation, and tool-chip constant length on the rake faces also varies with time. Thus, the cutting edges must undergo much greater mechanical load due to their more numerous entrances and exits in the work-piece. This may generate cracks, chipping, and cutting edge breakage. Consequently, it is critical to choose a cutting tool with sufficient toughness and a rigid cutting edge in order to make the impacts less harmful to the tool. To verify the feasibility and effectiveness of the heat pipe end-mill, it is very essential to investigate its structural static and dynamic characteristics under the actual working conditions.

As depicted above, only one of the three cutting edges is considered in this study thanks to the symmetric structure and the interrupted cutting process of the end-mill. The loads exerted on the tool are normally resolved into the three following directions: the $F_{t}$ in the circumferential direction, $F_{a}$ in the axial direction and $F_{r}$ in the radial direction, as illustrated in Fig. 15. Generally, $F_{t}, F_{a}$ and $F_{r}$ can result in the torsional deformation, the compressive deformation and the bending deflection of the endmill, respectively [3] and [14]. Consequently, this causes the various locations of the tip in the $x$-, $y$-, and $z$ directions, thereby resulting in poor machining accuracy and surface quality of the workpiece.

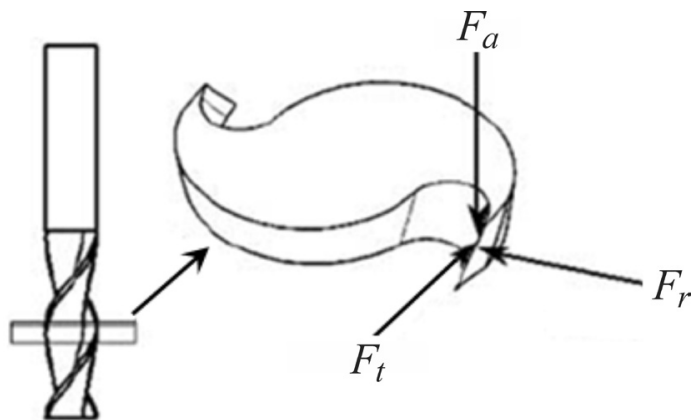

Fig. 15. Correlation of the cutting force components in end milling operations

\subsubsection{Static Stress \& Strain Distributions}

In view of the above-mentioned operation conditions, a clamp length, e.g. $9.29 \mathrm{~mm}$ was selected along the axis of the end mill (the red arrow in Fig. 16). The calculated results are presented in Figs. 16 to 18.

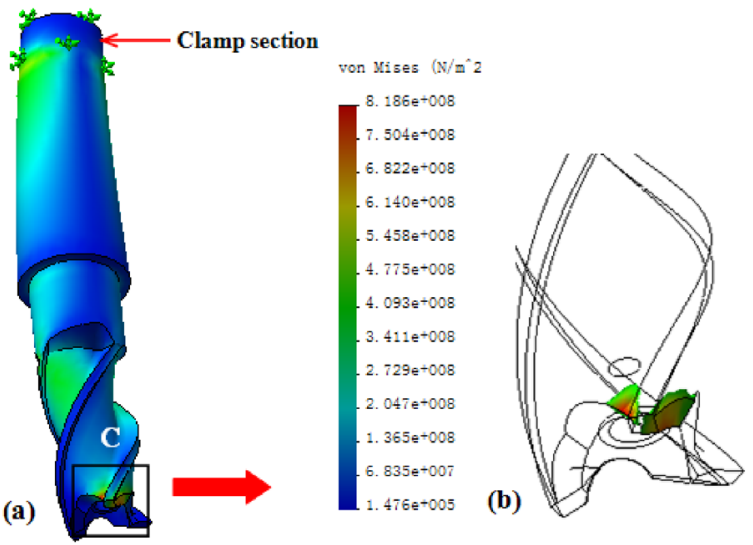

Fig. 16. a) Static stress distribution on the solid end-mill, b) detailed $\mathrm{C}$ of a); magnified view of the static stress on the tool

(a)
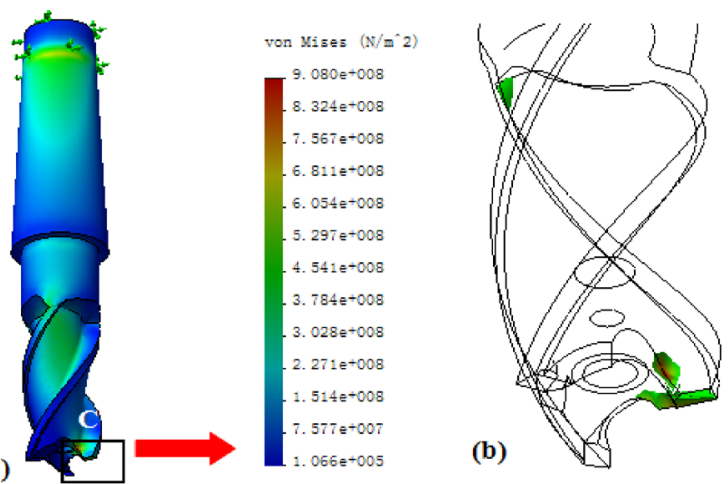

Fig. 17. a) Static stress distribution on the heat pipe end-mill; b) detailed $\mathrm{C}$ of a); magnified view of the static stress on the tool

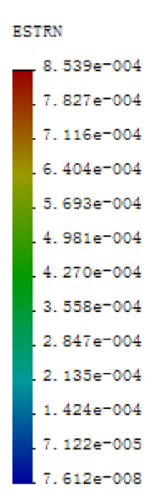

(a)
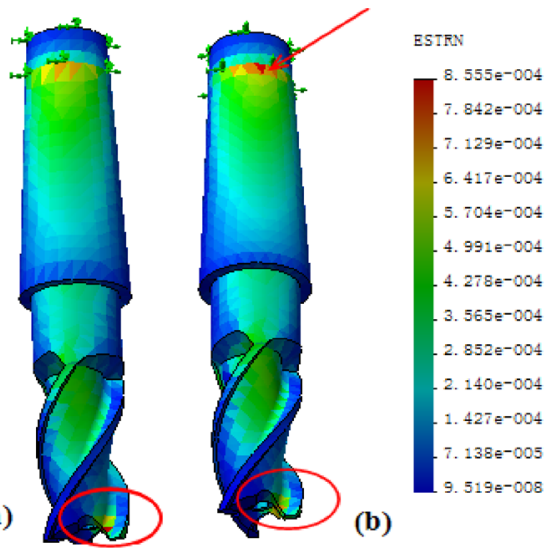

Fig. 18. Static strain distribution of the a) solid end-mill; and (b) heat pipe end-mill

For end milling, the pink static stresses, for the tool with or without heat-pipe cooling, both occur at the tool tip (Figs. 16 and 17). The maximum static stresses for heat-pipe tool and solid tool are 454.1 and 409.4 MPa, respectively. With heat pipe embedded in the tool, a roughly $10 \%$ increase in static stress compared with the solid tool. 
As illustrated in Fig. 18, the maximum strain for the solid tool only appears at the cutter tip (see the red ellipse); its value is $8.539 \times 10^{-4}$, while on the heat pipe cutter there exist two locations with the maximum strain, which is $8.555 \times 10^{-4}$. One also exists at the cutter tip, and the other appears at the clamp section (see the pink arrowhead).

As can be inferred from the above, the static stress and strain increase when the heat pipe end-mill is used. This is basically due to the fact that embedding a heat pipe in the solid tool decreases the inertia moment of the heat-pipe tool and, therefore, increases the related bending deformation and bending stress. Note that for hard alloy material used for the end-mill; however, its maximum bending strength is $1470 \mathrm{MPa}$, so the heatpipe tool in this study can satisfy the requirements of the milling operations. For the higher static stress and strain in the heat-pipe tool, the strength and stiffness of the main cutting zone, especially of the tool tip, could be improved by optimizing the geometric shape and configuration of the end-mill [3] and [14]. And also, it is found in the actual applications that optimizing the clamp length of the tool can lower the probability of the cutter resonating, especially of chattering and, consequently, decrease the bending deformation and bending stress [3] and [14]. This plays a critical role in extending the end-mill's lifetime.

\subsubsection{Structural Dynamic Analysis}

Mechanical impacts are also frequent in end milling operations due to the interrupted cutting inherent to it. The shocks and load variation on the tool gain importance and cause the chipping in the end of depth of cut area, which has deleterious effects on either the dimensional accuracies of the workpiece or the lifetime of the end milling operation system. Therefore, it is very essential to perform a structural dynamic analysis on the heat pipe end-mill.

In view of the actual vibrating state of the endmill, fifteen modes shapes are presented in this study dependent on the loads illustrated in Fig. 6. Fig. 19 shows vibration states of the solid end-mill. The frequencies are shown in Table. 1

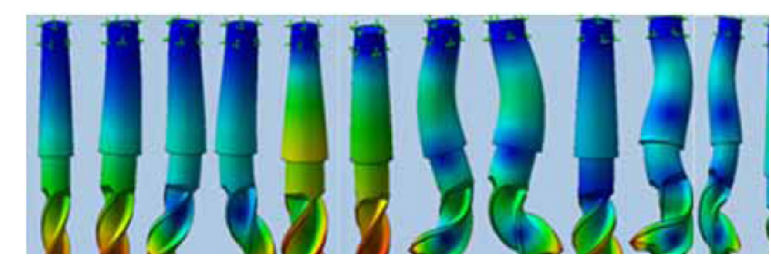

Fig. 19. Mode shapes of a tool without a heat pipe
Compared the vibration modes of the solid endmill with those of the heat pipe end-mill, it could be seen from Fig. 20 that the vibration modes of the solid tool are a little higher than those of the heat pipe tool, which indicates that the solid end-mill deforms smaller than the heat pipe end-mill in the actual applications. This basically contributes to the fact that the higher frequency, for an end-mill in machining operations, leads to the larger rigidity. Significant vibration of the heat pipe tool may have deleterious effects on both the dimensional accuracy of a workpiece and the stability of the end milling operation system. All these could be improved by optimizing the milling speed. Furthermore, it is found in the industry applications that optimizing the clamp length of the end-mill does reduce the number of strong vibration modes in the end milling operations, thereby lowering the probability of the cutter resonating, especially of chattering [3] and [14].

Table 1. Frequencies of a tool without / with a heat pipe

\begin{tabular}{ccc}
\hline Frequency & Solid tool [Hz] & Heat-pipe tool [Hz] \\
\hline 1 & 1804.3 & 1855.7 \\
2 & 1806.2 & 1856.4 \\
3 & 7268.9 & 7234.9 \\
4 & 7273.4 & 7235.8 \\
5 & 10325 & 10319 \\
6 & 16115 & 16146 \\
7 & 16910 & 16894 \\
8 & 16916 & 16906 \\
9 & 20616 & 20413 \\
10 & 30031 & 29785 \\
11 & 30049 & 29791 \\
12 & 37398 & 36228 \\
13 & 41311 & 41241 \\
14 & 44032 & 43268 \\
15 & 44065 & 43279 \\
\hline
\end{tabular}

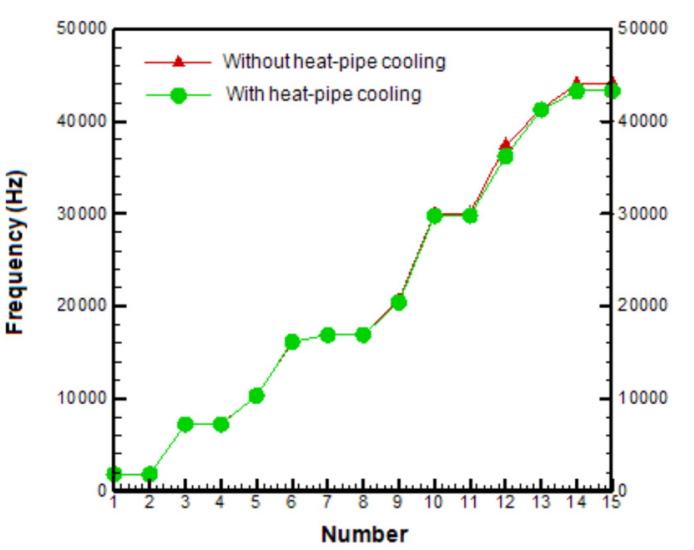

Fig. 20. Comparative vibration modes between a solid end-mill and a heat pipe end-mill under theclamp length $9.29 \mathrm{~mm}$ 


\section{CONCLUSION}

From thermal, structural static, and dynamic analyses points of view, the feasibility and effectiveness of the heat pipe end-mill were investigated. The numerical simulation results indicate that the peak temperature on the tool tip decreases from $1027^{\circ} \mathrm{C}$ for the solid end-mill to $737^{\circ} \mathrm{C}$ for the heat pipe end-mill by about $29 \%$ based on the equivalent amount of heat input, and that the maximum thermal stress also reduces from $650 \mathrm{MPa}$ for dry milling to $480 \mathrm{MPa}$ for the heat pipe cooling by an approximate factor of 1.4 under the same cooling conditions. This implies that the use of a heat pipe in the end milling processes can effectively perform thermal management comparable to the flooding coolant cooling used pervasively in the machining industry.

The use of a heat pipe embedded the solid end-mill may increase the static stress and strain at the cutter tip and enhance the vibration frequency/magnitude due to its hollow center. However, for end milling, the foregoing negative effects could be improved by optimizing the geometric shape, configuration and the clamp length of the heat pipe tool [3] and [11].

The numerical simulation evidences in this study therefore demonstrate that the use of heat pipe embedded in an end-mill is most feasible and effective and that the dry end milling can be achievable in the actual machining operations. Based on the results obtained in this work, several end mills with/without heat pipes have been manufactured and the results from testing are forthcoming in a future paper.

\section{ACKNOWLEDGEMENTS}

The authors would like to thank the financial support for the project from EPA-STAR grant through RD833357.

\section{REFERENCES}

[1] Braghini, A.Jr., Diniz, A.E., Filho, F.T. (2009). Tool wear and tool life in end milling of 15-5 PH stainless steel under different cooling and lubrication conditions. Journal of Advanced Manufacturing Technology, vol. 43, p. 756-764, DOI:10.1007/s00170-008-1744-6.

[2] Johnson, D. (1996). Why cutting tools fail. Tooling \& Production. Huebcore Communications Inc., Ohio.

[3] Trent, E., Wright, P. (2000). Metal Cutting. Butterworth/ Heinemann, Oxford.
[4] Ding, Y., Hong, S.Y. (1998). Improvement of chip breaking in machining low carbon steel by cryogenically pre-cooling the workpiece. ASME Journal of Manufacturing Science and Engineering, vol. 120, p. 76-83, DOI:10.1115/1.2830113.

[5] Peterson, G.P. (1994). An introduction to Heat Pipes: Modeling, Testing, and Applications, Wiley, New York.

[6] Jen, T.C., Chen, Y.M., Gutierrez, G. (2002). Investigation of heat pipe cooling in drilling applications. Part I: preliminary numerical analysis and verification. International Journal of Machine Tools \& Manufacture, vol. 42, p. 643-652, DOI:10.1016/S0890-6955(01)00155-9.

[7] Harley, C., Faghri, A. (1995). Two-Dimensional Rotating Heat Pipe Analysis. ASME Journal of Heat Transfer, vol. 117, no. 1, p. 202-208, DOI:10.1115/1.2822304.

[8] Ritcher, R., Gottschlich, J.M. (1994). Thermodynamics aspects of heat pipe operation. Journal of Thermodynamics and Heat Transfer, vol. 8, no. 2, p. 334-340, DOI:10.2514/3.543.

[9] Judd, R.L., MacKenzie, H.S., Elbestawi, M.A. (1995). An investigation of a heat pipe cooling system for use turning on a lathe. International Journal of Advanced Manufacturing Technology, vol. 10, no. 6, p. 357-366, DOI:10.1007/BF01179398.

[10] Lin, Z., Tien-Chien, J., Chen-Long, Y. (2009). Investigation of heat pipe cooling in drilling applications, part II: Thermal, structural static, and dynamic analyses. Proceedings of the ASME International Mechanical Engineering Congress \& Exposition, p. 1-8.

[11] Palmai, Z. (1987). Cutting temperature in intermittent cutting. International Journal of Machine Tool \& Manufacture, vol. 6, no. 2, p. 261-274, DOI:10.1016/ S0890-6955(87)80055-X.

[12] Tadic, B., Vukelic, D., Hodolic, J. (2011). Conservativeforce-controlled feed drive system for down milling. Strojniški vestnik - Journal of Mechanical Engineering, vol. 57, no. 5, p. 425-439, DOI:10.5545/ sv-jme.2009.055.

[13] Toh, C.K. (2005). Comparison of chip surface temperature between up and down milling orientations in high speed rough milling of hardened steel. Journal of Materials process Technology, vol. 167, p. 110-118.

[14] Shaw, M.C. (2005). Metal cutting principles. Oxford University Press, New York.

[15] Jen, T.C, Lavine, A.S. (1994). Prediction of tool temperature in interrupted metal cutting. Proceedings of the $7_{\text {th }}$ International Symposium on Transport Phenomena in Manufacturing Processes, p. 211-216.

[16] Stephenson, D.A., Ali, A. (1992). Tool temperatures in interrupted metal cutting. ASME Journal of Engineering for Industry, p. 127-136. 